\title{
Genetic Diversity Assessment and Identification of New Sour Cherry Genotypes Using Intersimple Sequence Repeat Markers
}

\author{
Roghayeh Najafzadeh, ${ }^{1}$ Kazem Arzani, ${ }^{1}$ Naser Bouzari, ${ }^{2}$ and Ali Saei ${ }^{3}$ \\ ${ }^{1}$ Department of Horticultural Sciences, Tarbiat Modares University (TMU), P.O. Box 14115-336, Tehran, Iran \\ ${ }^{2}$ Horticultural Section, Stone Fruit Research Group, Seed and Plant Improvement Research Institute of Karaj (SPII), \\ P.O. Box 31585-4119, Karaj, Iran \\ ${ }^{3}$ Genomics Section, Agricultural Biotechnology Research Institute of Iran (ABRII), P.O. Box 85135-487, Isfahan, Iran \\ Correspondence should be addressed to Roghayeh Najafzadeh; roghayehnajafzadeh@yahoo.com and \\ Kazem Arzani; arzani_k@modares.ac.ir
}

Received 19 January 2014; Accepted 2 February 2014; Published 10 March 2014

Academic Editor: Alexandre Sebbenn

Copyright (c) 2014 Roghayeh Najafzadeh et al. This is an open access article distributed under the Creative Commons Attribution License, which permits unrestricted use, distribution, and reproduction in any medium, provided the original work is properly cited.

\begin{abstract}
Iran is one of the chief origins of subgenus Cerasus germplasm. In this study, the genetic variation of new Iranian sour cherries (which had such superior growth characteristics and fruit quality as to be considered for the introduction of new cultivars) was investigated and identified using 23 intersimple sequence repeat (ISSR) markers. Results indicated a high level of polymorphism of the genotypes based on these markers. According to these results, primers tested in this study specially ISSR-4, ISSR-6, ISSR13, ISSR-14, ISSR-16, and ISSR-19 produced good and various levels of amplifications which can be effectively used in genetic studies of the sour cherry. The genetic similarity among genotypes showed a high diversity among the genotypes. Cluster analysis separated improved cultivars from promising Iranian genotypes, and the PCoA supported the cluster analysis results. Since the Iranian genotypes were superior to the improved cultivars and were separated from them in most groups, these genotypes can be considered as distinct genotypes for further evaluations in the framework of breeding programs and new cultivar identification in cherries. Results also confirmed that ISSR is a reliable DNA marker that can be used for exact genetic studies and in sour cherry breeding programs.
\end{abstract}

\section{Introduction}

The sour cherry belongs to the family of Rosaceae, subfamily Prunoideae, genus Prunus, and subgenus Cerasus [1]. It is an allotetraploid species $(2 n=4 x=32)$ resulting from a natural hybridization between Prunus avium L. (Sweet Cherry) and Prunus fruticosa Pall. (Ground Cherry) [2]. This species is reported to have originated from the area that comprises Asia Minor, Iran, Iraq, and Syria [3] and has been used as rootstock and also in breeding programs for developing new commercial cultivars, dwarf, and resistant rootstocks [4-6]. According to the FAO database, Iran ranked third worldwide in 2011 for cherry production after Turkey and the USA with a total of 241 thousand tons produced [7].

Genetic variability is a prerequisite for any plant breeding program [8]. As an origin of the subgenus Cerasus, Iran has rich cherry germplasm resources. Using diverse Cerasus subgenus resources to broaden the genetic base of cherry cultivars and rootstocks and improving them for development of the cherry industry are important goals for cherry breeders in Iran $[9,10]$. Therefore, it is necessary to characterize and preserve these genotypes and cultivars [11]. DNA markers are very useful in distinguishing between accessions and in investigations of genetic diversity or relatedness [12]. Different DNA markers have been broadly used to analyze genetic variations in Prunus, such as RAPD [13], AFLP [14], and SSR [15]. The major limitations of these methods are low reproducibility of RAPD, high cost of AFLP, and the need to know the flanking sequences to develop species specific primers for SSR polymorphism [16]. In comparison, intersimple sequence repeats (ISSRs) have been developed that overcome most limitations [17]. These markers involve 
TABLE 1: Accessions of genotypes used in this study and their origins.

\begin{tabular}{lcc}
\hline Number & Accession & Origin \\
\hline 1 & KaThLalSSGe21 & Lavasan \\
2 & Hamedan & Hamedan \\
3 & KaTaJo2Ge9 & Taleghan \\
4 & KaThMe3Ge19 & Chalus \\
5 & KaThLa8Ge31 & Lavasan \\
6 & KrRIV4C20 & Kerman \\
7 & EsASC1V1SS1 & Esfahan \\
8 & KaThLa3Ge23 & Lavasan \\
9 & Bulgar & Bulgaria \\
10 & Montmorency & France \\
11 & Erdi Jubileum & Hungary \\
12 & Erdi Botermo & Hungary \\
\hline
\end{tabular}

PCR amplification of DNA by a single, 16-18 bp long primer composed of a repeated sequence [18]. ISSR gives multilocus patterns which are very reproducible, abundant, and polymorphic in plant genomes [19]. It is useful in areas of cultivar identification, germplasm characterization, phylogenetic relationship analysis, and genetic linkage mapping in a wide range of plant species [20,21], including cherries [20-24].

In the present study, ISSR analysis was used to evaluate the genetic variation new Iranian sour cherries, with the aim of using the ISSR technique to these genotypes for the use them in cherries breeding programs as well as for conservation management of subgenus Cerasus germplasm in Iran. It is hoped that with supplementary tests and analyses we can identify and introduce new sour cherry cultivars to the fruit industry.

\section{Materials and Methods}

2.1. Plant Materials. During the breeding programs, collection, and evaluation of local sour cherry germplasms from different regions in Iran in order to achieve proper cultivars and rootstocks, after five years visual observations, it was found that some of the genotypes had quite superior growth characteristics and fruit quality that they can be considered for the introduction of new cultivars [25]. These superior genotypes were chance seedlings, so they were selected according to the 5-year visual observations and grafted onto "Mahlab" rootstocks which were available in the fruit research collection of the Seed and Plant Improvement Institute in Kamal Abad, Karaj, Iran. Then 2-year determination of the genotypes also approved it and showed that these selected genotypes had such superior growth characteristics and fruit quality [26]. In this study, these selected genotypes (see Table 1) and 4 improved cultivars (Bulgar, Montmorency, Erdi Jubileum, and Erdi Botermo) were analyzed. These genotypes were 5 years old and had been planted at $4 \times 5 \mathrm{~m}$. The young leaves of these genotypes were collected during May 2012. The characterization of the accessions is shown in Table 1.

2.2. DNA Extraction and PCR Amplification. Total genomic DNA was extracted from the young leaves using a CTAB (hexadecyl trimethyl ammonium bromide) method, according to the protocol described in Saunders et al. [27]. Then, the DNA extract was suspended in $50 \mu \mathrm{L} 1 \mathrm{X}$ TE buffer $(1 \mathrm{M}$ $\mathrm{pH}$ 8.0 Tris- $\mathrm{HCl} ; 0.5 \mathrm{M}$ pH 8.0 EDTA) and kept at $-20^{\circ} \mathrm{C}$. The quality and concentration of each DNA sample was determined using a NanoDrop spectrophotometer at 260, $280 \mathrm{~nm}$ (ND-1000, Co, USA) and running $3 \mu \mathrm{L}$ DNA in $0.7 \%(\mathrm{w} / \mathrm{v})$ agarose gels in 0.5X TAE buffer. 30 ISSR primers which were selected by Agricultural Biotechnology Research Institute Laboratory, Esfahan, Iran, according to [21, 22, 24, 28, 29] studies and synthesized by Metabion Co. (Germany) were used. These synthesized ISSR primers were initially screened and finally 23 primers were selected to be used in this study. The list of primers and their information are presented in Table 2. For PCR analysis, approximately $25 \mathrm{ng}$ of genomic DNA was used in a $25 \mathrm{~mL}$ reaction containing $1 \mathrm{X}$ PCR reaction buffer, $2 \mathrm{mM} \mathrm{MgCl}_{2}, 0.8 \mathrm{mM}$ dNTPs, 5 pmol of each primer, $1 \mathrm{U}$ Taq DNA polymerase (Fermentas, Lithuania), and DNA-free water. Amplifications were performed in a thermocycler (Applied Biosystems, Veriti, USA) programmed for a first denaturation step of $3 \mathrm{~min}$ at $94^{\circ} \mathrm{C}$, followed by 40 cycles of $30 \mathrm{~s}$ at $94^{\circ} \mathrm{C}$ for denaturation, $30 \mathrm{~s}$ at $30-57^{\circ} \mathrm{C}$ (varied for each primer according to Table 2) for annealing, $1 \mathrm{~min}$ at $72^{\circ} \mathrm{C}$ for elongation, and final extension at $72^{\circ} \mathrm{C}$ for $5 \mathrm{~min}$. They were then held at $4^{\circ} \mathrm{C}$ until the tubes were removed. Amplified products were separated by electrophoresis in $1.5 \%(\mathrm{w} / \mathrm{v})$ agarose gels at constant voltage $(95 \mathrm{~V})$ in $1 \mathrm{X}$ TAE buffer for approximately $90 \mathrm{~min}$, stained with gelred, and photographed with UV light (Figure 1). The size of produced fragments was defined according to size marker (GeneRuler $1 \mathrm{~kb}$ DNA ladder, SM0311, Fermentas).

2.3. Data Analysis. Only reproducible and well-defined alleles were considered potential polymorphic markers. The alleles scored as present (1) or absent (0) with Phoretix Pro, ver. 10.4 software. In order to increase the accuracy of the scoring, each gel electrophoresis was scored in three replications. The cophenetic correlation coefficient (CCC) was calculated and the similarity matrix was used for the cluster analysis and construction of dendrogram using the Simple Coefficient and Unweighted Pair-Group Method with Arithmetic average (UPGMA) [30] and for genetic relationships among subgenera and sections, Principal Coordinate Analysis (PCoA) and three-dimensional projection of genotypes (3D) [31] were used using the NTSYS software ver. 2.02 [32]. The following parameters were calculated for each primer: number of total alleles per locus, number of polymorphic alleles, polymorphism percentage, Polymorphism Information Content (PIC), average gene diversity (Hi), and fragment size. Polymorphism percentage was calculated using the ratio of number of polymorphic alleles to total alleles [33]. PIC was calculated as described by Warburton and Crossa [34] $\left(\mathrm{PIC}=1-\sum\left(P_{i} / P_{k}\right)^{2}\right)$, where $P_{i}$ is the proportion of the population carrying the $i$ th allele calculated for each microsatellite locus and $P_{k}$ is total alleles. Average gene diversity was calculated by direct counts for the putative locus, identified by each primer described by the IPGRI and Cornell University [33] method $\left(H_{i}=1-p 2-q 2\right)$, where $p$ and $q$ are the frequency of the $i$ th allele. 
TABLE 2: 23 ISSR primers used in this study and their results.

\begin{tabular}{|c|c|c|c|c|c|c|c|c|c|}
\hline \multicolumn{2}{|c|}{ NumberPrimers } & \multirow{2}{*}{$\begin{array}{c}\text { Sequence }\left(5^{\prime}-3^{\prime}\right) \\
\text { GTGGTGGTGGC }\end{array}$} & \multirow{2}{*}{$\begin{array}{l}\mathrm{TA}^{1} \\
\left({ }^{\circ} \mathrm{C}\right) \\
30\end{array}$} & \multirow[t]{2}{*}{$\begin{array}{c}\text { Total } \\
\text { number } \\
\text { of } \\
\text { alleles } \\
(a) \\
16\end{array}$} & \multirow{2}{*}{$\begin{array}{l}\text { Number of } \\
\text { polymor- } \\
\text { phic alleles } \\
(b) \\
16\end{array}$} & \multirow{2}{*}{$\begin{array}{c}\% \\
\begin{array}{c}\text { Polymorphism } \\
(b / a) \times 100\end{array} \\
100\end{array}$} & \multirow{2}{*}{$\begin{array}{r}\mathrm{PIC}^{2} \\
0.90\end{array}$} & \multirow[t]{2}{*}{$\begin{array}{c}\text { Average } \\
\text { gene } \\
\text { diversity } \\
\text { (Hi) }\end{array}$} & \multirow{2}{*}{$\begin{array}{r}\text { Band size } \\
\text { range (bp) }\end{array}$} \\
\hline 1 & ISSR-1 & & & & & & & & \\
\hline 2 & ISSR-2 & GAGAGAGAGAGAGAGAT & 48 & 21 & 21 & 100 & 0.94 & 0.40 & $400-1500$ \\
\hline 3 & ISSR-3 & СТСТСТСТСТСТСТСТG & 47 & 25 & 24 & 96.00 & 0.94 & 0.43 & $700-2500$ \\
\hline 4 & ISSR-4 & GAGAGAGAGAGAGAGATG & 52 & 26 & 26 & 100 & 0.94 & 0.37 & $400-1400$ \\
\hline 5 & ISSR-5 & AGAGAGAGAGAGAGAGTT & 52 & 21 & 21 & 100 & 0.94 & 0.36 & $400-2100$ \\
\hline 6 & ISSR-6 & СТСТСТСТСТСТG & 39 & 29 & 29 & 100 & 0.94 & 0.40 & $400-2200$ \\
\hline 7 & ISSR-7 & СТСТСТСТСТСТСТСТТG & 47 & 18 & 17 & 94.44 & 0.93 & 0.37 & $700-1700$ \\
\hline 8 & ISSR-8 & CACACACACACAAC & 39 & 25 & 24 & 96.00 & 0.95 & 0.40 & $700-2300$ \\
\hline 9 & ISSR-9 & CACACACACACAGT & 39 & 18 & 18 & 100 & 0.89 & 0.39 & $700-2800$ \\
\hline 10 & ISSR-10 & CACACACACACAGG & 36 & 21 & 21 & 100 & 0.94 & 0.37 & $400-1700$ \\
\hline 11 & ISSR-11 & CACACACACACAAG & 30 & 23 & 23 & 100 & 0.94 & 0.43 & $700-3000$ \\
\hline 12 & ISSR-12 & CACACACACACACACAGG & 47 & 15 & 14 & 93.33 & 0.88 & 0.43 & $500-2100$ \\
\hline 13 & ISSR-13 & СТСТСТСТСТСТСТСTRG & 53 & 29 & 29 & 100 & 0.96 & 0.34 & $400-2800$ \\
\hline 14 & ISSR-14 & DBDACACACACACACAC & 55 & 29 & 29 & 100 & 0.95 & 0.42 & $400-2800$ \\
\hline 15 & ISSR-15 & НVНТССТССТССТССТССТССТСС & 57 & 9 & 7 & 77.77 & 0.85 & 0.45 & $600-1800$ \\
\hline 16 & ISSR-16 & GAGAGAGAGAGAGAGAC & 53 & 25 & 25 & 100 & 0.95 & 0.45 & $400-3200$ \\
\hline 17 & ISSR-17 & ACACACACACACACACC & 53 & 17 & 17 & 100 & 0.90 & 0.44 & $600-2200$ \\
\hline 18 & ISSR-18 & GAGAGAGAGAGAGAGAYC & 47 & 15 & 14 & 93.33 & 0.90 & 0.45 & $600-1800$ \\
\hline 19 & ISSR-19 & AGAGAGAGAGAGAGAGYT & 52 & 29 & 29 & 100 & 0.95 & 0.41 & $280-1600$ \\
\hline 20 & ISSR-20 & ACACACACACACACACYG & 53 & 16 & 16 & 100 & 0.90 & 0.43 & $400-2800$ \\
\hline 21 & ISSR-21 & CACACACACACACACART & 48 & 24 & 24 & 100 & 0.94 & 0.39 & $600-1700$ \\
\hline 22 & ISSR-22 & GAGAGAGAGAGAGAGAYG & 47 & 20 & 20 & 100 & 0.93 & 0.40 & $400-2200$ \\
\hline 23 & ISSR-23 & GAGAGAGAGAGAGAGACG & 55 & 18 & 18 & 100 & 0.94 & 0.42 & $400-3200$ \\
\hline & Mean & - & - & 21.26 & 20.95 & 98.45 & 0.93 & 0.41 & - \\
\hline & Total & - & - & 489 & 482 & - & - & - & - \\
\hline
\end{tabular}

Note: $D=(G, A, T), B=(G, T, C), H=(A, T, C), V=(G, A, C), R=(A, G), Y=(C, T)$, and $N=(A, T, G, C)$.

${ }^{1}$ Annealing temperature. ${ }^{2}$ Polymorphism Information Content.

\section{Results}

The results of ISSR fingerprinting of 12 sour cherry genotypes using 23 primers are given in Table 2. Results showed that 489 alleles were generated at 23 ISSR loci, 482 of which were polymorphic. The number of total alleles per locus varied from 9 (ISSR-15 loci) to 29 (ISSR-6, ISSR-13, ISSR14 , and ISSR-19 loci) alleles with an average of 21.26 across the genotypes. Other primers with a high number of alleles per locus were ISSR-4 (26 alleles) followed by ISSR-3, ISSR8 , and ISSR-16 (25 alleles). The average polymorphic alleles per primer were 20.95 , and of the 23 loci, ISSR-6, ISSR13, ISSR-14, and ISSR-19 loci had the highest polymorphic alleles ( 29 alleles), followed by ISSR-4 (26 alleles), ISSR16 (25 alleles), and ISSR-3 and ISSR-8 (24 alleles). The polymorphism percentage for primers ranged from $77.77 \%$ to $100.0 \%$ with an average of $98.45 \%$ (Table 2).
PIC values ranged from 0.85 to 0.96 with an average of 0.93. The highest PIC, that is, an indicator of effectiveness of primers used in genetic diversity studies, was ISSR-13 (0.96) with 29 alleles, followed by ISSR-8, ISSR-14, ISSR-16, and ISSR-19 (0.95). The lowest PIC value belonged to ISSR-15 (0.85) with (7 alleles) (Table 2). Average gene diversity ranged from 0.34 to 0.45 with a mean of 0.41 . Among the loci, the highest $H_{i}$ value belonged to the ISSR-1, ISSR-15, ISSR-16, and ISSR-18 locus (0.45), while the lowest values belonged to the ISSR-13 loci (0.34) (Table 2). Fragment size of the 23 primers ranged from 280 to $3200 \mathrm{bp}$. The lowest ranges were those of ISSR-19 (280-1600) and ISSR-4 (400-1400), and the highest range was related to ISSR-16 and ISSR-23 (4003200) bp (Table 2).

The highest cophenetic correlation coefficient based on ISSR data with a simple similarity coefficient was $(r=0.91)$ (Table 3). The high value of this coefficient indicates the 


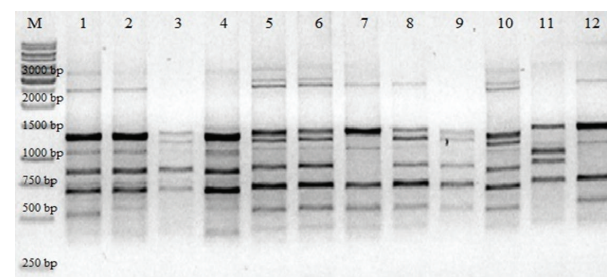

FIGURE 1: ISSR band profiles generated by the primer ISSR-16. Genotype number: see Table 1. M: weight marker: $1 \mathrm{~kb}$ DNA.

TABLE 3: Comparison of different methods for constructing similarity matrices and dendrograms.

\begin{tabular}{lccc}
\hline $\begin{array}{l}\text { Similarity } \\
\text { coefficient }\end{array}$ & UPGMA & UPGMC & $\begin{array}{c}\text { Complete } \\
\text { linkage }\end{array}$ \\
\hline $\mathrm{D}$ & $r=0.72$ & $r=0.42$ & $r=0.71$ \\
$\mathrm{~J}$ & $r=0.74$ & $r=0.47$ & $r=0.73$ \\
SM & $r=0.91$ & $r=0.24$ & $r=0.79$ \\
\hline
\end{tabular}

D: Dic [36]; J: Jaccard [37]; SM: Simple Matching [30].

UPGMA: Unweighted Pair-Group Method with Arithmetic average; UPGMC: Unweighted Pair-Group Method using Centroids.

suitability of the grouping method. The CCC is considered to be a good representation of the data matrix in the dendrogram if it is $0.80 \leq$ CCC [35]. Thus, the similarity matrix was used for the cluster analysis and construction of dendrogram using the simple coefficient and UPGMA.

Genetic similarity between genotypes was estimated using the simple similarity coefficient. The genetic similarity ranged from 0.56 to 0.77 with an average of 0.72 . It showed a high diversity among genotypes. The EsASC1V1SS1 and Bulgar showed the lowest similarity (0.56), and the KaThMe3Ge19 and KaThLa8Ge31 showed a high similarity (0.77). Other genotypes such as Bulgar with KaTaJo2Ge9 (0.58), KrRIV4C20 (0.59), and Erdi Botermo (0.59) had low similarity. Moreover, KaThLa8Ge31 with KrRIV4C20 (0.75), Erdi Jubileum (0.75) and KaThLa3Ge23 (0.76), KaTaJo2Ge9 with KrRIV4C20 (0.76), and Ka ThMe3Ge19 with Erdi Botermo (0.76) had high similarity (Table 4$)$.

A dendrogram based on the simple similarity coefficient and UPGMA analysis is presented in Figure 2. According to the dendrogram, genotypes were separated into two main clusters. Promising Iranian genotypes were separated from the improved cultivars and were further divided into eight subclusters with a genetic similarity of 0.72 . One (I) included the KaThLalSSGe21 genotype (from Lavasan), two (II) included Hamedan (Hamedan), and subcluster three (III) contained KaTaJo2Ge9 (Taleghan) and KrRIV4C20 (Kerman). These two genotypes were similar to the matrix 0.76 , so it seemed that they had the same genetic origin. Subcluster 4 (IV) which was the biggest subcluster included KaThMe3Ge19 (Chalus), KaThLa8Ge31 (Lavasan), KaThLa3Ge23 (Lavasan), and Erdi Botermo (Hungary). Five (V) included the Erdi Jubileum cultivar (Hungary); six (VI) included EsASC1V1SS1 (Esfahan); seven (VII) included the Bulgar (Bulgaria); eight (III) included Montmorency cultivar

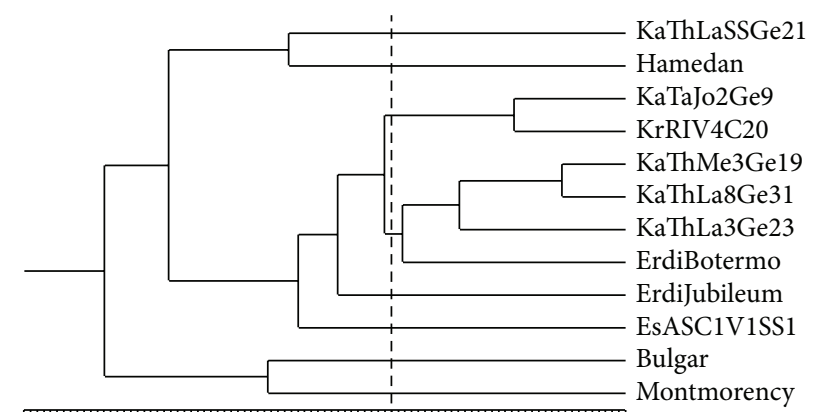

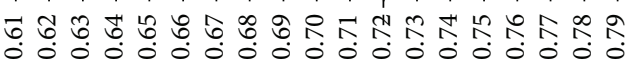

FIGURE 2: Dendrogram of ISSR analysis on sour cherry genotypes used in this study.

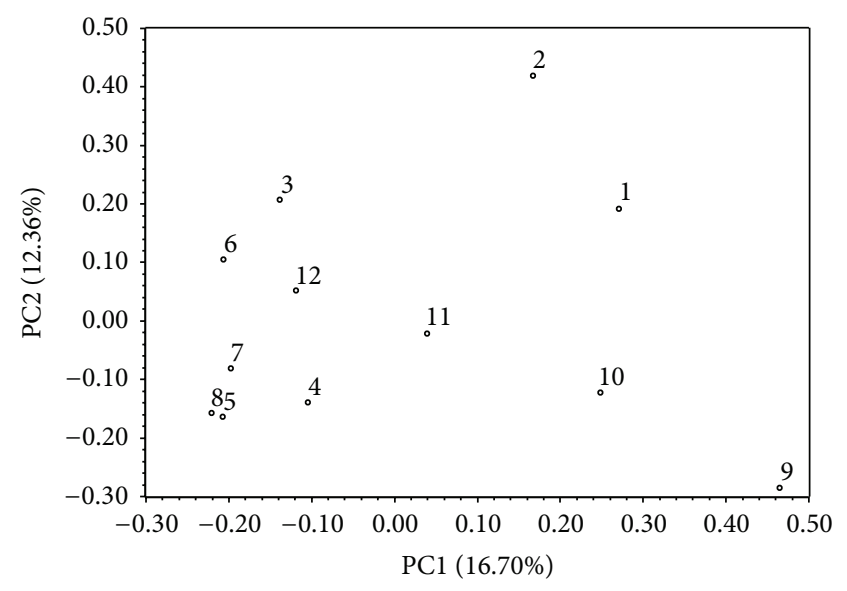

FIgURE 3: Principle coordinate analysis (PCoA) for 23 ISSR primers applied on sour cherry genotypes. Numbers represent the genotypes according to Table 1 .

(France). According to these results, it seems that the genetic diversity of the sour cherry genotypes was not entirely a function of geographical variation; thus, the genotypes of the 4th subgroup with different distribution centers were placed in adjacent genetic groups.

The genetic relationship between these genotypes was also visualized by performing PCoA that showed two significant axes, which explained $16.70 \%$ and $12.36 \%$ of the total variance, respectively. The first two eigenvalues accounted for $29.06 \%$ of the variation observed in the genotypes (Table 5).

The two-dimensional plot generated from PCoA also supported the clustering pattern of the UPGMA dendrogram (Figure 3). This reflected a higher genetic diversity in the studied collection, which was confirmed by a principle component analysis of the genotype data. Results of this analysis showed a wider genetic distribution of genotypes in the studied collection.

In the three-dimensional PCoA plot, generally, similar groupings with the UPGMA dendrogram and additional information were also revealed. The first three principal axes accounted for $16.70 \%, 12.36 \%$, and $10.52 \%$ of the total variation, respectively, indicating the complex multidimensional nature of ISSR variation (Figure 4). 
TABLE 4: The simple similarity matrix for sour cherry genotypes based on ISSR data.

\begin{tabular}{lccccccccccc}
\hline & 1 & 2 & 3 & 4 & 5 & 6 & 7 & 8 & 9 & 10 & 11 \\
\hline 1 & 1.00 & & & & & & & & & & \\
2 & 0.69 & 1.00 & & & & & & & & \\
3 & 0.67 & 0.70 & 1.00 & & & & & & & \\
4 & 0.67 & 0.64 & 0.71 & 1.00 & & & & & & \\
5 & 0.64 & 0.64 & 0.72 & 0.77 & 1.00 & & & & & \\
6 & 0.63 & 0.67 & 0.76 & 0.70 & 0.75 & 1.00 & & & & \\
7 & 0.64 & 0.63 & 0.66 & 0.69 & 0.72 & 0.69 & 1.00 & & & \\
8 & 0.63 & 0.63 & 0.73 & 0.72 & 0.76 & 0.71 & 0.73 & 1.00 & & \\
9 & 0.64 & 0.60 & 0.58 & 0.64 & 0.61 & 0.59 & 0.56 & 0.60 & 1.00 & \\
10 & 0.66 & 0.66 & 0.66 & 0.66 & 0.69 & 0.64 & 0.64 & 0.66 & 0.68 & 1.00 & \\
11 & 0.70 & 0.68 & 0.70 & 0.70 & 0.75 & 0.70 & 0.68 & 0.70 & 0.64 & 0.70 & 1.00 \\
12 & 0.65 & 0.67 & 0.73 & 0.76 & 0.72 & 0.71 & 0.67 & 0.69 & 0.59 & 0.67 & 0.68 \\
\hline
\end{tabular}

Genotype number: see Table 1.

TABLE 5: Eigen values, percentage, and cumulative proportions for 11 principal coordinate axes, derived from ISSR markers application on sour cherry genotypes.

\begin{tabular}{lccc}
\hline Axes & Eigen value & Percent & Cumulative \\
\hline 1 & 1.15 & 16.70 & 16.70 \\
2 & 0.94 & 12.36 & 29.06 \\
3 & 0.90 & 10.52 & 39.59 \\
4 & 0.88 & 9.84 & 49.43 \\
5 & 0.82 & 8.98 & 58.42 \\
6 & 0.77 & 8.60 & 67.02 \\
7 & 0.75 & 8.00 & 75.03 \\
8 & 0.72 & 7.35 & 82.39 \\
9 & 0.66 & 6.56 & 88.95 \\
10 & 0.63 & 5.99 & 94.94 \\
11 & 0.61 & 5.05 & 100.00 \\
\hline
\end{tabular}

\section{Discussion}

Iran is accepted as an origin and diversity center for cherries. In this study, we report for the first time the use of ISSR markers to assess the genetic characterization and to determine genetic relationships between promising Iranian sour cherry genotypes selected from different regions of Iran and improved cultivars. In the present study, 23 ISSR loci in sour cherry genotypes were assayed. The results obtained showed that ISSR primers can be effectively used for genetic diversity studies as well as genetic identification of sour cherries, which was also found in other investigations of cherries [20-24]. In fact, primers tested in this study produced good and various levels of amplifications.

A total of 489 amplified products were obtained using 23 ISSR primers. The average number of total alleles per locus identified in this study (21.26) was higher than the number identified in other studies of cherries. Average polymorphism percentage across all genotypes was $98.45 \%$ indicating a high level of polymorphism. Among the 23 loci, ISSR-6, ISSR-13, ISSR-14, and ISSR-19 had the highest polymorphic alleles. Shahi-Gharahlar et al. [24] in their study of 12 ISSR primers

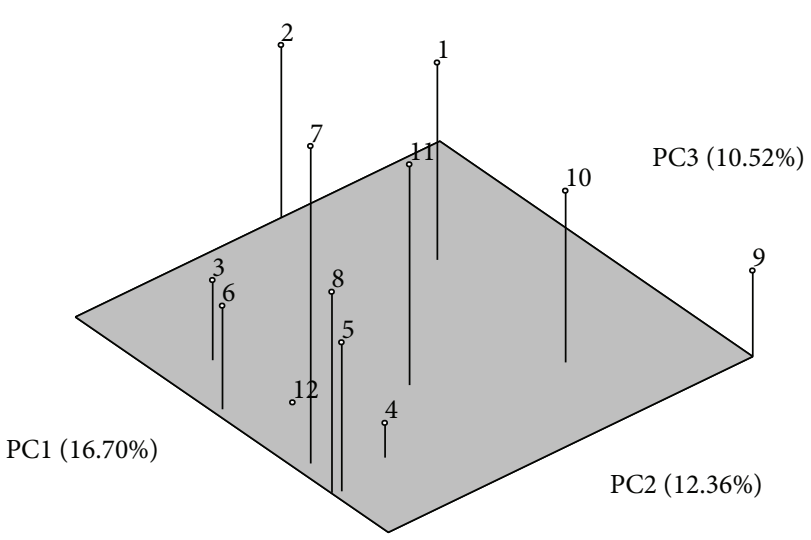

FIGURE 4: 3D plot for 23 ISSR primers applied on sour cherry genotypes. Numbers represent the genotypes according to Table 1.

tested on 39 accessions of Iranian wild Prunus sub-cerasus reported that these ISSR primers generated 156 alleles and that the number of alleles per locus ranged from 9 to 19 with an average of 13 alleles, and the polymorphism percentage was $81.80-100 \%$ with an average of $96.46 \%$. Ganopoulos et al. [20] studied 10 ISSR primers on 19 Greek traditional sweet cherries and two international cultivars. They reported that these ISSR primers generated 91 alleles and that the number of alleles per locus ranged from 2 to 10 with an average of 9.1 alleles, and the polymorphism percentage was $25-75 \%$ with an average of $57.7 \%$. Moreover, Li et al. [22] studied 18 ISSR primers on 10 Chinese sour cherries and reported that these ISSR primers generated 150 alleles and that the number of alleles per locus ranged from 4 to 13 with an average of 8.33 alleles, and the polymorphism percentage was $1.33-32 \%$ with an average of $18.67 \%$. The high number of generated alleles in our study may be due to the use of several different genotypes that had high genetic diversity.

The PIC values ranged from 0.85 to 0.96 with a mean value of 0.93 . The high value of PIC represents the larger number of alleles and polymorphism [18]. Yilmaz et al. [21] in their study of 20 ISSR primers tested on 16 genotypes from 
genus Prunus reported that PIC ranged from 0.35 to 0.93 with an average of 0.74 . The average gene diversity ranged from 0.34 to 0.45 with a mean of 0.41 . Ganopoulos et al. [20] reported that gene diversity ranged from 0.29 to 0.48 with an average of 0.36 . This particular average gene diversity value (0.41) was higher than that (0.36) identified in another survey [20]. The high $h_{i}$ showed a high diversity among sour cherry genotypes. Fragment size of the 23 primers ranged from 280 to $3200 \mathrm{bp}$. Band size ranges using ISSR markers were also found in other investigations of cherries with the range of 530-3100 bp [20], 231-1986 bp [22], 400-1950 bp [23], and 200-2100 bp [24].

According to these results, primers tested in our study produced good and various levels of amplifications as compared to other studies. For example, Shahi-Gharahlar et al. [24] in their study on subgenus Cerasus used ISSR-2 primer and reported that this primer produced 12 total alleles with polymorphism percentage of $91.70 \%$ and fragment size of 250 to $1200 \mathrm{bp}$, while in our study this primer produced 21 total alleles with polymorphism percentage of $100 \%$ and size range of 400-1500 bp. Also Li et al. [22] used ISSR-20 primer in sour cherries and reported that this primer produced 7 total alleles with size range of 281-1458 bp, while this primer produced 16 total alleles with polymorphism percentage of $100 \%$ and size range of 400-2800 bp in our study. Moreover, Yilmaz et al. [21] tested ISSR-3 and ISSR-18 primers in genus Prunus and reported that these primers produced 13 and 9 total alleles with polymorphism percentage of 100 and $89 \%$, respectively, while we found that these primers produced 25 and 15 total alleles with polymorphism percentages of 96 and $93 \%$, respectively. Also these primers have been tested by other researchers in various species. For example, Sofalian et al. [28] studied ISSR-2, ISSR-3, and ISSR-5 primers on wheat accessions. They reported that these primers produced 3,15 , and 10 total alleles, respectively, while the total alleles produced by these primers in our study were higher than their study. Moreover, Acharya and Sharma [29] in their study on genus Papaver tested these primers and reported that ISSR-1, ISSR6, ISSR-8, ISSR-10, ISSR-11, and ISSR-19 did not produce any band, while in our study these primers produced good and various levels of amplifications. So ISSR-6 and ISSR-19 had the highest number of alleles (29 alleles). The highest number of alleles in their study related to ISSR-2 (4 alleles) and ISSR-3 (6 alleles). Our results indicated a high level of polymorphism of the genotypes based on these markers specially primers with high numbers of polymorphic alleles, polymorphism percentage, PIC values, and gene diversity were to ISSR-4, ISSR-6, ISSR-13, ISSR-14, ISSR-16, and ISSR-19, which can be used effectively in genetic diversity studies of the sour cherry.

Autochthonous varieties, cultivars, and wild genotypes are rich resources for genes for breeding objectives [10, 11]. The mean number of alleles produced by Iranian genotypes was higher than the number of alleles produced by foreign genotypes. These results indicated that since the Iranian genotypes were not selected for breeding programs, they were more likely to have a more diverse genetic background, and they can be used to select different genotypes in order to produce new cultivars. The high average gene diversity with a mean of 0.41 and the high number of alleles observed with a mean of 21.26 for all loci showed that these ISSR markers are highly polymorphic and can be useful in the study of genetic diversity.

Genetic similarity between genotypes ranged from 0.56 to 0.77 with an average of 0.72 , which showed a high diversity among the genotypes. Cluster analysis with a genetic similarity of 0.72 divided the genotypes into eight distinct groups that separated Iranian genotypes from improved cultivars, and PCoA supported the cluster analysis results. These genotypes grouped within the same cluster in the dendrogram also occupied the same positions in two-dimensional scaling. Shahi-Gharahlar et al. [24] reported that the genetic similarity measured within 39 accessions of subcerasus ranged from 0.04 to 0.85 with an average of 0.28 . A dendrogram constructed according to ISSR data of these genotypes divided them into 11 subclusters in which improved cherry cultivars were separated from wild genotypes, and this is consistent with the results of our study.

\section{Conclusions}

In summary, the good discrimination efficiency and high reproducibility of ISSR markers make them particularly suitable to identify the closely related and unknown sour cherry genotypes. In addition, the high genetic diversity observed within superior Iranian sour cherry genotypes and improved cultivars reflects the necessity for the conservation of this germplasm. Since the Iranian genotypes were superior to the improved cultivars and were separated from them in most of the groups, these genotypes can be considered as distinct genotypes for further evaluations in the framework of breeding programs and new cultivar identification in cherries. Hence, it is expected that the results of this study will assist current sour cherrybreeding efforts in Iran and will maintain the genetic integrity of the genetic resources. It is hoped that with supplementary tests and analyses we can identify and introduce new sour cherry cultivars to the fruit industry.

\section{Conflict of Interests}

The authors declare that there is no conflict of interests regarding the publication of this paper.

\section{Acknowledgments}

Materials for this study were provided and partially supported by Grant no. (0-100-120000-04-0000-84104) with the support of the Seed and Plant Improvement Institute, Horticultural Section, Karaj, Islamic Republic of Iran. The authors would like to thank Tarbiat Modares University (TMU) for providing the facilities.

\section{References}

[1] N. E. Looney and A. D. Webster, Cherries: Crop Physiology, Production and Uses, CAB International Press, Oxfordshire, UK, 1996.

[2] A. F. Lezzoni, H. Schmidt, and A. Albertini, "Cherries," in Genetic Resources of Temperate Fruit and Nut Crops, J. N. Moore 
and J. R. Ballington, Eds., pp. 109-175, Society for Horticultural Science, Wageningen, The Netherland, 1991.

[3] N. I. Vavilov, The Origin, Variation, Immunity and Breeding of Cultivated Plants, Ronald Press, New York, NY, USA, 1951.

[4] G. Charlot, M. Edin, F. Flochlay, P. Soing, and C. Boland, "Tabel Edabriz: a dwarf rootstock for intensive cherry orchards," Acta Horticulturae, vol. 667, no. 1, pp. 217-222, 2005.

[5] K. Hrotko, L. Magyar, and M. Gyeviki, "Evaluation of native hybrids of Prunus fruticosa Pall. As cherry interstocks," Acta Agriculturae Serbica, vol. 13, pp. 41-45, 2008.

[6] L. Magyar and K. Hrotkó, "Prunus cerasus and prunus fruticosa as interstocks for sweet cherry trees," Acta Horticulturae, vol. 795, pp. 287-292, 2008.

[7] FAOSTAT, FAOSTAT, FAO Statistical Databases (United Nations), FAO, 2013, http://faostat.fao.org/.

[8] G. S. Khush, "Molecular genetics-plant breeder's perspective," in Molecular Techniques in Crop Improvement, S. M. Jain, D. S. Brar, and B. S. Ahloowalia, Eds., pp. 1-8, Kluwer Academic, Dordrecht, The Netherlands, 2002.

[9] E. Ganji-Moghadam and A. Khalighi, "Relationship between vigor of Iranian Prunus mahaleb L. selected dwarf rootstocks and some morphological characters," Scientia Horticulturae, vol. 111, no. 3, pp. 209-212, 2007.

[10] A. Shahi-Gharahlar, Z. Zamani, M. R. Fatahi, and N. Bouzari, "Assessment of morphological variation between some Iranian wild Cerasus sub-genus genotypes," Horticulture, Environment and Biotechnology, vol. 51, no. 4, pp. 308-318, 2010.

[11] H. Demirsoy and L. Demirsoy, "Characteristics of some local sweet cherry cultivars from Homeland," Journal of Agronomy, vol. 3, no. 2, pp. 88-89, 2004.

[12] G. Lacis, I. Rashal, S. Ruisa, V. Trajkovski, and A. F. Iezzoni, "Assessment of genetic diversity of Latvian and Swedish sweet cherry (Prunus avium L.) genetic resources collections by using SSR (microsatellite) markers," Scientia Horticulturae, vol. 121, no. 4, pp. 451-457, 2009.

[13] Y. L. Cai, D. W. Cao, and G. F. Zhao, "Studies on genetic variation in cherry germplasm using RAPD analysis," Scientia Horticulturae, vol. 111, no. 3, pp. 248-254, 2007.

[14] D. Struss, R. Ahmad, S. M. Southwick, and M. Boritzki, "Analysis of sweet cherry (Prunus avium L.) cultivars using SSR and AFLP markers," Journal of the American Society for Horticultural Science, vol. 128, no. 6, pp. 904-909, 2003.

[15] M. Bouhadida, A. M. Casas, M. J. Gonzalo, P. Arús, M. Á. Moreno, and Y. Gogorcena, "Molecular characterization and genetic diversity of Prunus rootstocks," Scientia Horticulturae, vol. 120, no. 2, pp. 237-245, 2009.

[16] A. Belaj, Z. Satovic, G. Cipriani et al., "Comparative study of the discriminating capacity of RAPD, AFLP and SSR markers and of their effectiveness in establishing genetic relationships in olive," Theoretical and Applied Genetics, vol. 107, no. 4, pp. 736744, 2003.

[17] K. Wu, R. Jones, L. Danneberger, and P. A. Scolnik, "Detection of microsatellite polymorphisms without cloning," Nucleic Acids Research, vol. 22, no. 15, pp. 3257-3258, 1994.

[18] W. Powell, G. C. Machray, and J. Proven, "Polymorphism revealed by simple sequence repeats," Trends in Plant Science, vol. 1, no. 7, pp. 215-222, 1996.

[19] B. Bornet and M. Branchard, "Nonanchored Inter Simple Sequence Repeat (ISSR) markers: reproducible and specific tools for genome fingerprinting," Plant Molecular Biology Reporter, vol. 19, no. 3, pp. 209-215, 2001.
[20] I. V. Ganopoulos, K. Kazantzis, I. Chatzicharisis, I. Karayiannis, and A. S. Tsaftaris, "Genetic diversity, structure and fruit trait associations in Greek sweet cherry cultivars using microsatellite based (SSR/ISSR) and morpho-physiological markers," Euphytica, vol. 181, no. 2, pp. 237-251, 2011.

[21] K. U. Yilmaz, S. Ercişli, B. M. Asma, Y. Doğan, and S. Kafkas, "Genetic relatedness in prunus genus revealed by inter-simple sequence repeat markers," HortScience, vol. 44, no. 2, pp. 293297, 2009.

[22] M. M. Li, Y. L. Cai, Z. Q. Qian, and G. F. Zhao, "Genetic diversity and differentiation in Chinese sour cherry Prunus pseudocerasus Lindl., and its implications for conservation," Genetic Resources and Crop Evolution, vol. 56, no. 4, pp. 455-464, 2009.

[23] A. Lisek and E. Rozpara, "Identification and genetic diversity assessment of cherry cultivars and rootstocks using ISSR-PCR technique," Journal of Fruit and Ornamental Plant Research, vol. 17, no. 2, pp. 95-106, 2009.

[24] A. Shahi-Gharahlar, Z. Zamani, R. Fatahi, and N. Bouzari, "Estimation of genetic diversity in some Iranian wild Prunus subgenus Cerasus accessions using inter-simple sequence repeat (ISSR) markers," Biochemical Systematics and Ecology, vol. 39, no. 4-6, pp. 826-833, 2011.

[25] N. Bouzari, E. Ganji-Moghadam, F. Karami et al., National Project Collection and Evaluation of Local Sour Cherry Germplasms in Order To Achieve Proper rootsTock and Cultivars, Project No. 0-100-120000-04-0000-84104, Seed and Plant Improvement Institute, Horticultural Section, Karaj, Iran; Agricultural Research and Educatin Organization Press, Tehran, Iran, 2010.

[26] N. Najafzadeh, K. Arzani, and N. Bouzari, "Assesment of morphological and pomological variation of some selected Iranian sour cherry (Prunus cerasus L.) genotypes,' Seed and Plant, vol. 1, no. 2, pp. 123-137, 2014.

[27] J. A. Saunders, M. J. Pedroni, L. D. J. Penrose, and A. J. Fist, "AFLP analysis of opium poppy," Crop Science, vol. 41, no. 5, pp. 1596-1601, 2001.

[28] O. Sofalian, N. Chaparzadeh, A. Javanmard, and M. S. Hejazi, "Study the genetic diversity of wheat landraces from northwest of Iran based on ISSR molecular markers," International Journal of Agriculture and Biology, vol. 10, no. 4, pp. 466-468, 2008.

[29] H. S. Acharya and V. Sharma, "Molecular characterization of opium poppy (Papaver somniferum) germplasm," American Journal of Infectious Diseases, vol. 5, no. 2, pp. 148-153, 2009.

[30] P. H. A. Sneath and R. R. Sokal, Numerical Taxonomy, the Principles and Practice of Numerical Classification, Freeman WH, San Francisco, Calif, USA, 1973.

[31] S. A. Mohammadi and B. M. Prasanna, "Analysis of genetic diversity in crop plants-salient statistical tools and considerations," Crop Science, vol. 43, no. 4, pp. 1235-1248, 2003.

[32] F. G. Rohlf, NTsys-Pc Numerical Taxonomy and Multivariate System Version 2.0 Applied, vol. 12, Biostatistics, New York, NY, USA, 2000.

[33] IPGRI and Cornell University, Genetic Diversity Analysis With Molecular Marker Data: Learning Module, Measures of Genetic Diversity, IPGRI, Maccarese, Rome; Cornell University, Ithaca, NY, USA, 2003.

[34] M. Warburton and J. Crossa, Data Analysis in the CIMMYT. Applied Biotechnology Center for Fingerprinting and Genetic Diversity Studies, CIMMYT, Mexico City, Mexico, 2002.

[35] H. C. Romesburg, Cluster Analysis for Researchers, Krieger, Malabar, Fla, USA, 1990, Reprint of 1984 edition. 
[36] N. M. Nei and W. Li, "Mathematical model for studying genetic variation in terms of restriction endonucleases," Proceedings of the National Academy of Sciences of the United States of America, vol. 76, no. 10, pp. 5269-5273, 1979.

[37] P. Jaccard, "Nouvelles recherches sur la distribution florale," Bulletin de la Societe Vaudoise des Sciences Naturelles, vol. 44, pp. 223-270, 1908. 

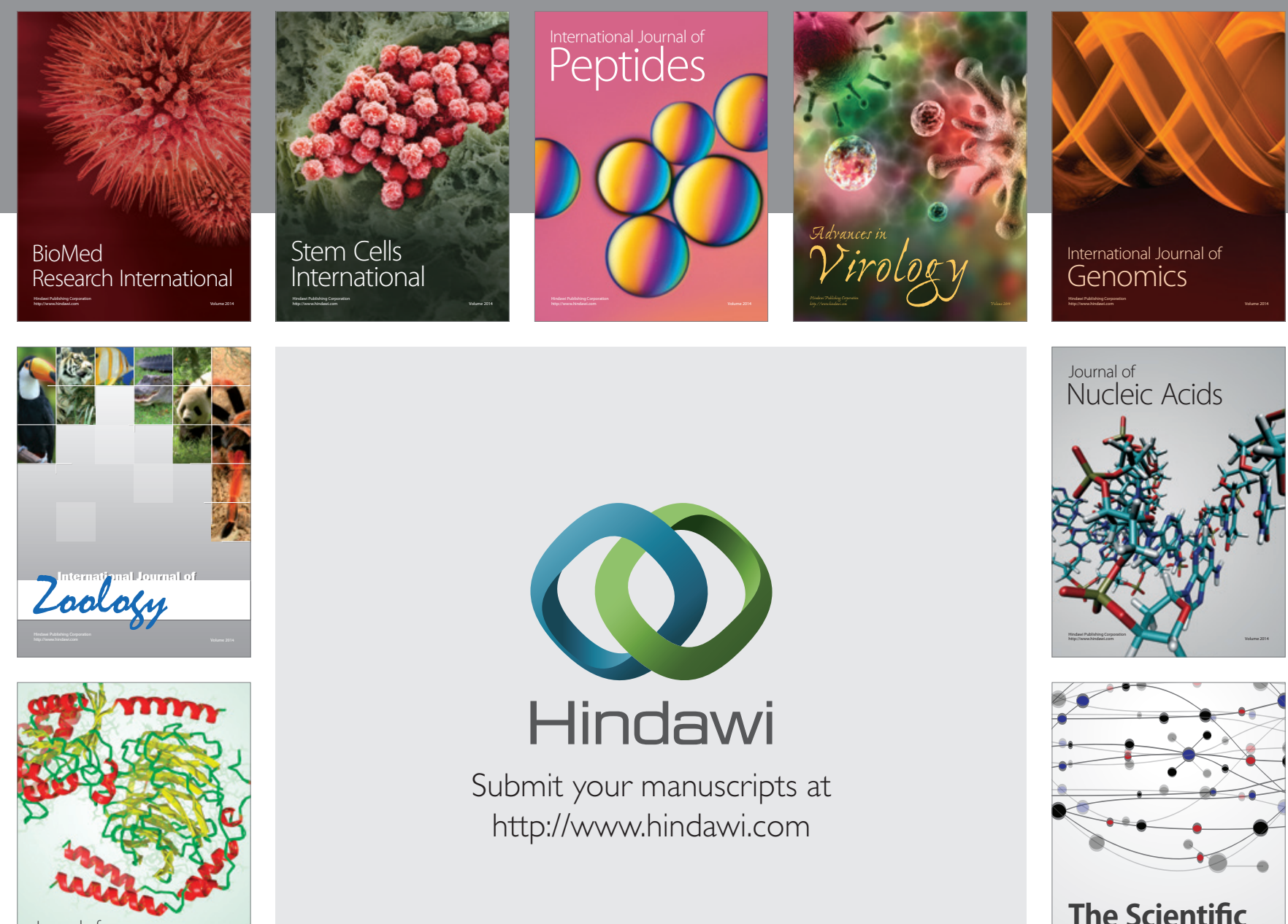

Submit your manuscripts at

http://www.hindawi.com

Journal of
Signal Transduction
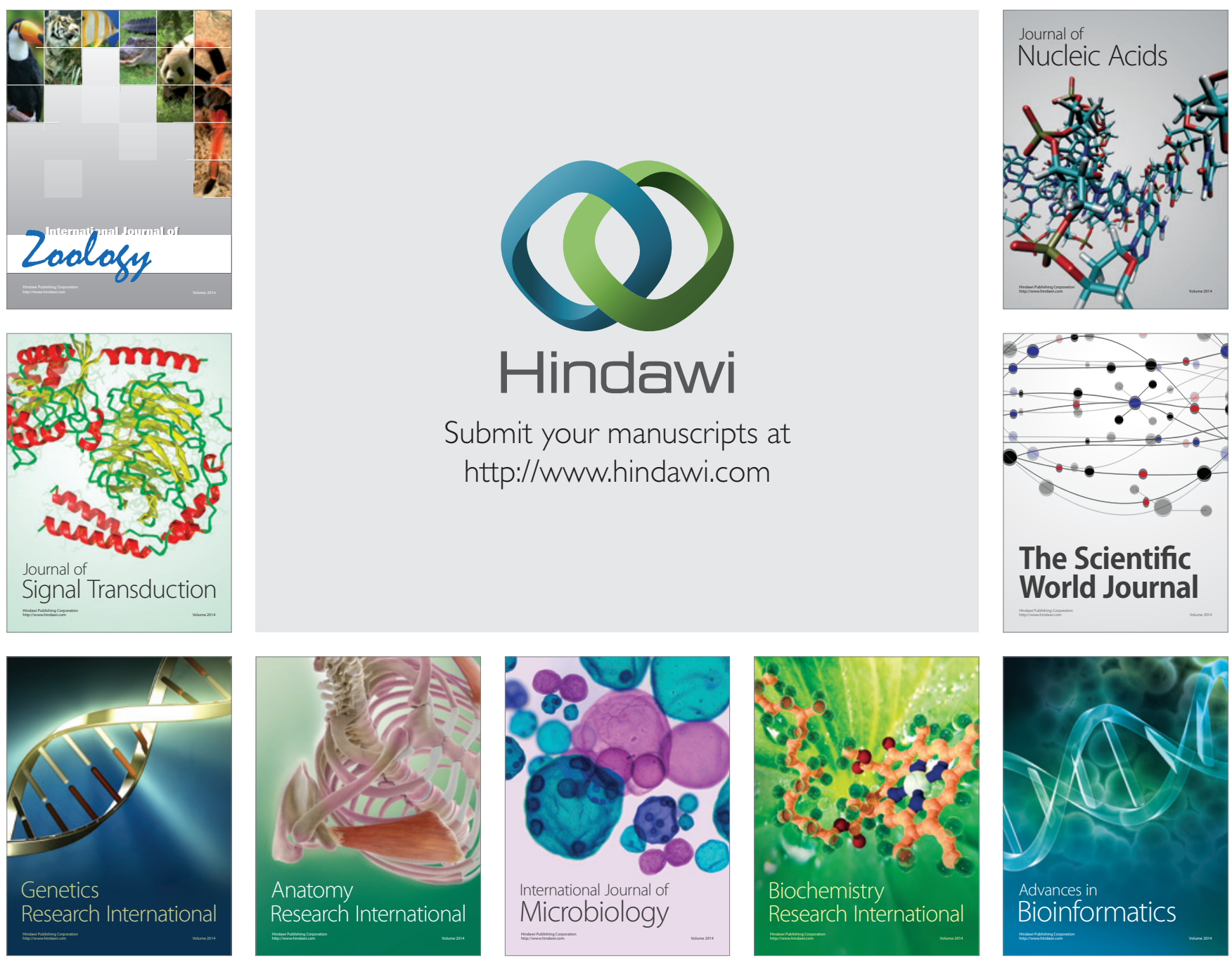

The Scientific World Journal
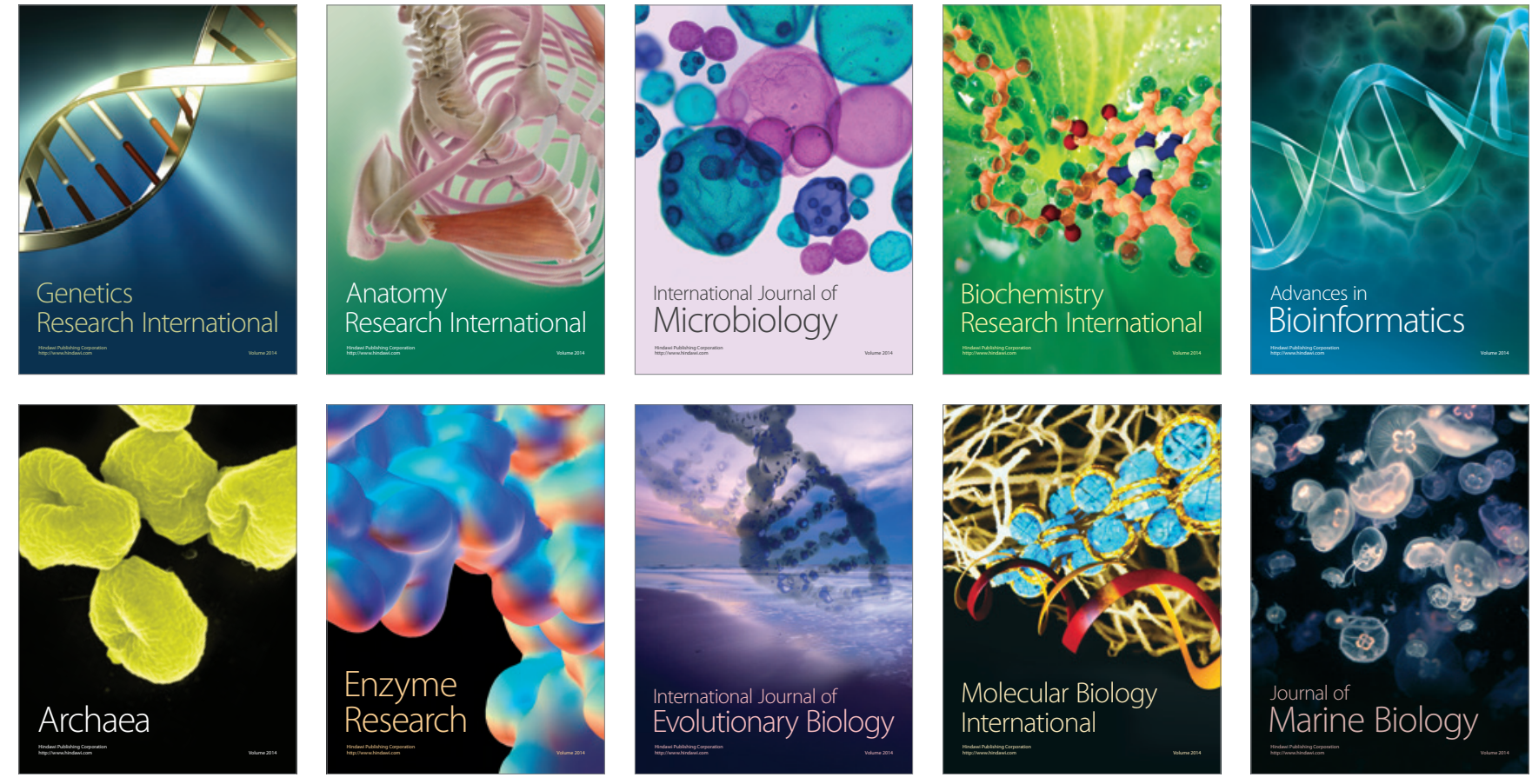